\title{
EMPREENDEDORISMO E DESENVOLVIMENTO NOS MUNICÍPIOS PARANAENSES - UMA ANÁLISE DOS INDICADORES
}

\author{
ENTREPRENEURSHIP AND DEVELOPMENT IN THE CITIES OF \\ PARANA - AN ANALYSIS OF THE RECENT INDICATORS
}

\author{
Rosana Dalla Costa Félix ${ }^{1}$ \\ Moisés Francisco Farah Júnior ${ }^{2}$
}

\begin{abstract}
RESUMO
O Brasil é caracterizado por um processo histórico de desenvolvimento concentrado nos grandes centros. As desigualdades regionais se acentuaram com o processo de industrialização no Paraná, indicando que as políticas de atração de investimentos, especialmente na década de 1990, falharam em resolver esse problema. Para evitar o esvaziamento das cidades periféricas e o êxodo para os grandes centros, é necessário que os municípios encontrem meios próprios de se desenvolverem, e o incentivo ao empreendedorismo é considerado um caminho que pode ser adotado como uma política pública pelos prefeitos. Este artigo busca descrever o nível de empreendedorismo dos 399 municípios paranaenses e relacioná-lo com o grau de desenvolvimento socioeconômico de cada localidade. Para verificar este fenômeno, utilizou-se os indicadores de 2010 mesurados pelo Índice de Desenvolvimento Municipal para a Micro e Pequena Empresa (IDMPE) do Sebrae e pelo Índice Firjan de Desenvolvimento Municipal (IFDM) da Firjan. Adotou-se a metodologia de Análise Exploratória de Dados (AED) e o coeficiente de correlação de Pearson. Encontrou-se indicações de uma alta correlação entre as variáveis empreendedorismo (medido pelo Sebrae) e o desenvolvimento local (medido pela Firjan). A correspondência é ainda mais elevada quando se analisa apenas o componente de emprego e renda no IFDM.
\end{abstract}

Palavras-chave: Empreendedorismo; Desenvolvimento local; Paraná.

\begin{abstract}
Brazil is marked by a historic process of development concentrated in major centers. The regional inequalities have widened with the process of industrialization in the state, indicating that the policies of investments attraction, in particular on the decade of 1990, failed to solve this problem. To avoid the emptying of the peripheral cities and the exodus to major centers, it is necessary that the cities find their own ways to develop, ant the incentive to entrepreneurship is considered a path that can be adopted by the mayors as a public politic. This article aims to describe the entrepreneurship level of the 399 cities of Parana and relate to the socio-economic development degree of each locality. To verify this phenomenon, it was utilized available indicators for 2010 provided by Sebrae-PR and Firjan. The methodology used was the Exploratory Analysis of Data (AED), beyond the correlation of Pearson. It was found evidences that exists a strong correlation between the variables entrepreneurship, measured by Municipal Development Index for Micro and Small Companies (IDMPE) from Sebrae,

\footnotetext{
${ }^{1}$ Jornalista e especialista em Relações Internacionais pela FAE (2004). Aluna do Mestrado Profissional de Planejamento e Governança Pública da Universidade Tecnológica Federal do Paraná (UTFPR), repórter e colunista do jornal Gazeta do Povo de Curitiba.

2 Economista e doutor em Engenharia de Produção pela Universidade Federal de Santa Catarina (UFSC) (2002). Professor Adjunto Nível 1 com dedicação exclusiva à UTFPR, professor da disciplina Políticas Públicas e Sustentabilidade do Mestrado Profissional de Planejamento e Governança Pública.
} 
with the local development, measured by Firjan Index of Municipal Development (IFDM). The correlation is strongest when analyzing only the employment and income component in IFDM.

Keywords: Entrepreneurship; Local development; Paraná.

\section{Introdução}

A história do Brasil é marcada por um processo de urbanização concentrado nas capitais e em alguns municípios-polo. Nesse cenário, cidades de médio e pequeno porte têm dificuldade para atrair indústrias e outros setores geradores de emprego e renda. Este processo tem causado uma série de prejuízos à comunidade local, que, muitas vezes, precisa se deslocar a outro município para encontrar oportunidades de trabalho.

Para evitar o esvaziamento populacional e a estagnação econômica do município, é fundamental que as cidades periféricas busquem caminhos para o desenvolvimento sustentável. O comprometimento da comunidade local é muito importante nesse processo, mas ela somente se tornará efetiva e eficaz se receber apoio de arranjos institucionalizados capitaneados pelo poder público. $\mathrm{O}$ incentivo ao empreendedorismo se insere nesses arranjos e pode ser uma alternativa para os governos promoverem o desenvolvimento local.

Os governantes que resolvem adotar esse caminho não necessitam de um prévio conhecimento especializado. Em todo o Brasil, o Serviço Brasileiro de Apoio às Micro e Pequenas Empresas do Sebrae oferece consultoria especializada para o fomento ao empreendedorismo, que se dá principalmente pela adoção da Lei Geral da Microempresa, uma obrigação comum a todos os municípios brasileiros.

O objetivo primordial do Sebrae, como o próprio nome diz, é auxiliar na criação e no desenvolvimento de pequenas empresas. Mas, para que isso ocorra, é fundamental a participação governamental e, por isso, o Sebrae oferece projetos específicos para infundir nos governantes a importância do fomento ao empreendedorismo. Desde 2001, a entidade reconhece os gestores que atingem esse objetivo, concedendo-lhes o Prêmio Prefeito Empreendedor. Além disso, o Sebrae produz rotineiramente manuais e guias sobre o tema, para auxiliar os gestores e os potenciais empreendedores a trilharem o caminho do desenvolvimento.

No Paraná, o Sebrae criou, em 2008, o Índice de Desenvolvimento Municipal para a Micro e Pequena Empresa (IDMPE), que avalia o desenvolvimento local a partir do ambiente institucional e socioeconômico de cada localidade. O levantamento foi realizado em três edições (2008, 2009 e 2010) e leva em conta uma série de indicadores - não apenas aqueles que medem o empreendedorismo, como o da taxa de abertura de novas empresas, mas também os indicadores educacionais e fiscais de cada município.

O objetivo deste artigo é analisar o IDMPE dos 399 municípios paranaenses e comparar o desempenho de cada localidade com outros indicadores sociais que compõem o Índice de Firjan de Desenvolvimento Municipal (IFDM), com o intuito de responder à seguinte questão: o empreendedorismo pode auxiliar no desenvolvimento dos municípios do Paraná?

O estudo é relevante porque pretende verificar a relação entre dois indicadores recentes, disponíveis para todos os municípios do Paraná e, a partir daí, buscar uma alternativa de política pública de desenvolvimento local. Para atingir este objetivo, este artigo está estruturado em sete capítulos: (1) introdução, (2) desenvolvimento regional, (3) 
considerações sobre o empreendedorismo, (4) metodologia adota, (5) resultados, (6) conclusões finais e (7) bibliografia.

\section{Desenvolvimento econômico}

O Brasil, devido a sua extensão continental, enfrenta grandes desafios para promover o desenvolvimento em todo o seu território. Essa dificuldade já surgiu durante o período da colonização portuguesa. Segundo Figueiredo e Leite (2006), a época foi caracterizada pela criação de poucos polos regionais que tinham vínculo direto com Portugal e quase nenhuma relação com outras colônias brasileiras.

Macedo et al. (2002) fazem um histórico do desenvolvimento regional da economia brasileira baseado em quatro fases delimitadas por Antonio Carlos Galvão e Ronaldo Vasconcelos (1999): isolamento relativo ou arquipélago regional, articulação comercial, articulação produtiva e desenvolvimento regional difuso. A primeira fase diz respeito aos sistemas de exportação de manufaturas espalhadas por diversas regiões brasileiras ao longo do século XVI até o início do século XX. Em seguida, o Brasil passou por uma fase de industrialização, concentrada no Sudeste do Brasil. A partir da década de 1970, entra-se na fase de articulação produtiva, com a desconcentração espacial das atividades econômicas, da qual o Paraná participou, principalmente com a instalação de várias indústrias na recém-criada Cidade Industrial de Curitiba (MACEDO et al. 2002).

A última fase, iniciada na década de 1980, é assinalada pela emergência de "ilhas de produtividade": as cidades que já tinham um desenvolvimento considerável continuaram a atrair novos investimentos. Conforme afirma Diniz (1995 apud MACEDO et al., 2002, p. 7):

No caso do Brasil, a concentração industrial prévia e a desigualdade do potencial de pesquisa e de renda dificultam um processo de desconcentração industrial para as regiões pobres ou vazias. Assim considerando, não resta dúvida de que as melhores condições para a localização de atividades de alta tecnologia estão predominantemente no Estado de São Paulo e secundariamente no corredor que vai de Belo Horizonte a Porto Alegre.

A evolução da economia paranaense pode ser analisada a partir dessas quatro fases (MACEDO et al., 2002): a exploração da erva-mate (isolamento relativo); expansão da economia cafeeira e fornecimento de produtos ao mercado consumidor de São Paulo (articulação comercial); expansão da indústria em complementaridade com São Paulo (articulação produtiva); e diversificação da estrutura industrial com adensamento das relações interindustriais (desenvolvimento regional difuso).

Essas fases geraram um desenvolvimento desigual, que pode ser observado em todo o Brasil e, mais especificamente, no Paraná. A desigualdade entre os municípios paranaenses é a mais alta da região Sul e foi diretamente influenciada pelos diferentes ciclos colonizadores no estado, sempre baseados na exploração dos recursos naturais - alguns em fase bem recente (SILVA et al., 2009).

Mesmo recentemente, as decisões governamentais foram incapazes de reverter essa desigualdade e, na verdade, até contribuíram para o agravamento da situação. Silva e Michon Jr. (2008), ao analisarem os indicadores socioeconômicos do Paraná na década de 1990, concluíram que houve avanços entre o período de 1991 a 2000. Entretanto, os autores assinalam que a melhoria nos indicadores concentrou-se em Curitiba e na região metropolitana, devido à política de incentivos fiscais adotada pelo governo estadual à época, a 
qual não demonstrou "preocupação de descontração regional, já historicamente existente entre as mesorregiões do estado" (SILVA; MICHON, 2008, p. 42). Conclusão semelhante é observada por Macedo et al. (2002), ao analisar os investimentos anunciados pelas empresas no Paraná ao longo da década de 1990.

\subsection{Desenvolvimento local}

A excessiva concentração da atividade econômica começa a enfrentar questionamentos e resistências, e o conceito de desenvolvimento local surge para tentar reverter esse cenário. O termo é definido como "um processo endógeno registrado em pequenas unidades territoriais e agrupamentos humanos capaz de promover o dinamismo econômico e a melhoria da qualidade de vida da população" (BUARQUE, 1999, p. 9).

Pode-se dizer que o desenvolvimento local é uma experiência recente no Brasil, já que, por muitas décadas, as ações nesse sentido foram ineficazes e conduzidas de forma totalmente desarticulada, conforme relatam Vaz e Caldas (2006 apud MARTINS et al., 2010). Segundo esse relato, a preocupação das autoridades com o tema iniciou-se no fim da década de 1970, época em que a luta pela redemocratização começou a ganhar força no Brasil. O desenvolvimento local é descrito por eles em três fases: 1976 a 1988, 1989 a 1992 e após 1993.

O primeiro período caracterizou-se por raras iniciativas em poucas cidades, porém elas tinham o mérito de integrar a comunidade na formulação e execução de políticas públicas eficientes. Contudo, a promulgação da Constituição de 1988 revolucionou o papel dos municípios - fase esta denominada de "a grande encruzilhada" (VAZ; CALDAS, 2006 apud MARTINS et al., 2010). Isso se deveu ao fato de que os municípios, ao mesmo tempo que se beneficiaram do aumento da arrecadação tributária própria, também receberam novas obrigações.

As pressões por atendimento às demandas reprimidas de infraestrutura urbana básica e serviços públicos e políticas sociais consumiam a maior parte da energia dos governantes municipais e dos recursos disponíveis nos municípios (MARTINS et al., 2006, p. 3).

As prefeituras passaram a se responsabilizar por ações de bem-estar social que antes cabiam à União ou aos governos estaduais, além de se verem obrigados a promover o desenvolvimento econômico local (ABRUCIO; COUTO, 1996).

A terceira fase distinguiu-se pela adoção de práticas gerenciais modernas em detrimento das políticas públicas direcionadas ao desenvolvimento local. A implantação do Plano Real, em 1994, logrou derrotar a inflação, porém isso afetou diretamente o caixa dos municípios que viram encolher seus ganhos financeiros da época da inflação elevada. Isto gerou menos receita e, ao mesmo tempo, o desemprego no Brasil crescia (MARTINS et al., 2006).

Tomasetto et al. (2009), citando o Institut de Formation em Développement Communautaire (IFDEC), resumem o desenvolvimento local como uma intervenção socioeconômica em que os cidadãos, sejam eles ligados ao setor privado, público ou social, são incentivados a exercer o empreendedorismo, potencializando o uso dos recursos locais. 
Partindo das definições de Buarque (1999), neste estudo enfoca-se o desenvolvimento municipal, que é um recorte espacial onde pode ocorrer o desenvolvimento local. Segundo este mesmo autor (BUARQUE, 1999, p.11):

O município tem uma escala territorial adequada à mobilização das energias sociais e integração de investimentos potencializadores do desenvolvimento, seja pelas reduzidas dimensões, seja pela aderência político-administrativa que oferece, através da municipalidade e instância governamental.

\section{Empreendedorismo e políticas públicas}

Com muitas responsabilidades e poucas oportunidades de atrair grandes empresas, a maioria dos municípios precisa percorrer um caminho alternativo para garantir o desenvolvimento socioeconômico. De acordo com Figueiredo e Leite (2006), as pesquisas mostram que mais importante do que a instalação de indústrias é a possibilidade de cada cidade desenvolver determinados talentos e capacidades de sua população, de forma a incentivar a inovação e o empreendedorismo. Para que esse ambiente surja em determinada localidade, é essencial a ação estatal.

Uma primeira dificuldade no estudo sobre os impactos do empreendedorismo é a sua definição, pois não há consenso sobre o termo. Porém, segundo Audrestsch e Keilbach (2004), isso se deve mais a um efeito de sua essência multidimensional. Esses autores apontam que a visão mais predominante é a de que o empreendedorismo está relacionado à percepção de novas oportunidades econômicas e sua posterior alocação no mercado.

Um conceito amplo é o de Rocha e Sternberg (2005) que, após a revisão da literatura sobre o tema, sustentam que o empreendedorismo pode ser conceituado como a "descoberta de oportunidades e a subsequente criação de uma nova atividade econômica, geralmente resultando na criação de novas organizações" (ROCHA; STERNBERG, 2005, p. 269).

Neste artigo, o empreendedorismo é analisado como inovação, criatividade e criação de novas organizações e/ou atividades - conceitos extraídos das áreas de economia e administração (MEZA, 2012). Segundo o economista Joseph Alöis Schumpeter (1883-1950), o empreendedor "não é um cientista criando uma nova invenção, mas é quem utiliza novos meios de produção de maneira inovadora, mais vantajosa" (DROUIN, 2008, p. 140).

Canever et al. (2010) ressaltam a falta de pesquisas sobre as consequências dos empreendedorismo no desenvolvimento local, devido a limitações conceituais e metodológicas, porém esse quadro tem mudado, inclusive pela necessidade de se incorporar o empreendedorismo como um elemento central na formulação de políticas públicas.

Assim como o empreendedorismo, o conceito de políticas públicas é amplo e multidisciplinar. Segundo Souza (2006, p. 26), "a formulação de políticas públicas constituise no estágio em que os governos democráticos traduzem seus propósitos e plataformas eleitorais em programas e ações que produzirão resultados ou mudanças no mundo real".

Entretanto, não são apenas os governos constituídos os responsáveis por políticas públicas. Adotando uma visão multicêntrica (LIMA, 2012), não importa quem vai executá-la, mas sim qual é o problema a ser enfrentado. "A perspectiva de política pública vai além da perspectiva de políticas governamentais, na medida em que o governo, com sua estrutura administrativa, não é a única instituição a servir à comunidade política, isto é, a promover "políticas públicas"” (HEIDEMANN, 2009, p. 31). 
De qualquer forma, cabe ao poder público organizar e fomentar o empreendedorismo. Quando isso ocorre, e cada localidade começa a explorar suas potencialidades, o domínio monopolista dos grandes centros dá lugar à interdependência. O novo modelo econômico deve estar baseado no surgimento de empresas criativas, que promovam constantemente essa inovação e as transformem em oportunidades de produção, emprego e renda.

Nessa perspectiva, abraçando a argumentação de Figueiredo e Leite (2006), é fundamental que o Estado aja de maneira a criar um ambiente favorável à dinâmica de inovação permanente. As instituições precisam promover o aprendizado social e encorajar os atores sociais a buscar e empreender novas oportunidades para a comunidade local.

Há diversas formas de o poder público incentivar o empreendedorismo. O Sebrae, por exemplo, no mais recente manual criado para orientar o prefeito empreendedor (Sebrae, 2013), elenca 100 passos a serem seguidos. Pelo fato de serem orientações extensas, apesar de práticas, não serão discutidas neste estudo.

Para os fins que este artigo se propõe, pode-se dizer que, de forma geral, há pelo menos quatro grandes ações (Tabela 1) que os governantes podem adotar para fomentar o empreendedorismo.

Ao tratar de políticas públicas, Frey (2000) faz uma observação pertinente, que poderia ser vista como limitadora ao trabalho aqui proposto. Segundo ele, o direito adquirido pelos municípios, em 1988, de poderem criar sua própria constituição local - conhecida como Lei Orgânica Municipal - gera uma infinidade de arranjos institucionais e governamentais possíveis no Brasil. Para Frey (2000, p. 243), apesar de as relações entre o Executivo e o Legislativo municipal não apresentarem grandes diferenças de um local para outro, há uma "multiplicidade institucional" que dificulta o estudo das políticas públicas a nível municipal.

Tabela 1 - Níveis de análise do empreendedorismo público

\begin{tabular}{|l|l|}
\hline \multicolumn{1}{|c|}{ Nível de Análise } & \multicolumn{1}{c|}{ Exemplos de ação } \\
\hline As “regras do jogo" & Novas leis, procedimentos administrativos e normas informais. \\
\hline $\begin{array}{l}\text { Novas organizações } \\
\text { públicas }\end{array}$ & $\begin{array}{l}\text { Criação de novas agências governamentais ou parcerias com } \\
\text { organizações não lucrativas, com fins públicos ou sociais. }\end{array}$ \\
\hline $\begin{array}{l}\text { Gestão criativa dos recursos } \\
\text { públicos }\end{array}$ & $\begin{array}{l}\text { Reorganização de recursos, mão de obra, serviços, por meio } \\
\text { dos órgãos já existentes ou novas parcerias. }\end{array}$ \\
\hline $\begin{array}{l}\text { Efeitos das ações privadas } \\
\text { sobre o domínio público }\end{array}$ & $\begin{array}{l}\text { Aproveitamento das condições favoráveis proporcionadas por } \\
\text { empresas ou grupos com interesse específico. }\end{array}$ \\
\hline
\end{tabular}

Fonte: Adaptado de KLEIN et al. apud MEZA (2012, p. 14).

Mas, independentemente do número de arranjos possíveis, os objetivos dos governantes devem ser os mesmos, isto é, o desenvolvimento e a melhora da qualidade de vida da população. Dessa forma, nas próximas seções serão discutidos os indicadores que podem refletir a decisão política local e os consequentes impactos no desenvolvimento do município. 


\section{Metodologia}

Utilizou-se a técnica de Análise Exploratória de Dados (AED), que consiste na coleta, análise, tratamento e descrição de um conjunto de dados. Segundo Nist (2001 apud CUNHA et al., 2002), a AED permite aprofundar a análise sobre um conjunto de dados, investigar hipóteses sobre a estrutura dos dados, detectar outliers (dados anormais ou inconsistentes) e verificar as relações entre as variáveis utilizadas.

\subsection{Coleta}

No presente estudo, adotou-se, para a totalidade dos municípios paranaenses (399) dois indicadores, ambos de 2010: o Índice de Desenvolvimento Municipal para a Micro e Pequena Empresa (IDMPE) do Sebrae e o Índice de Firjan de Desenvolvimento Municipal (IFDM).

O IDMPE foi criado pelo Sebrae, em 2008, com base no Índice de Desenvolvimento Humano (IDH), elaborado pela Organização das Nações Unidas (ONU) (SEBRAE, 2011). O indicador foi desenvolvido em parceria com o Instituto Brasileiro da Qualidade e Produtividade (IBQP) e pesquisadores da Universidade Federal do Paraná (UFPR), e é formado por três subíndices: 1) Índice de Desenvolvimento Empresarial (IDE), que mede o clima de negócios dentro do município; 2) Índice de Desenvolvimento de Mercado (IDM), capta a movimentação do mercado consumidor; e 3) Índice de Desenvolvimento Institucional (IDI), que indica as condições socioeconômicas e de infraestrutura existentes na localidade. Resumidamente, os itens componentes de cada um dos subindicadores são demonstrados na Tabela 2.

Tabela 2 - Variáveis dos componentes do IDMPE

\begin{tabular}{|c|c|}
\hline IDE & $\begin{array}{l}\text { PIB real } \\
\text { Variação do PIB real em relação ao ano anterior } \\
\text { Taxa de inatividade (estabelecimentos sem vínculos empregatícios) } \\
\text { Taxa de criação de estabelecimentos formais }\end{array}$ \\
\hline IDM & $\begin{array}{l}\text { Taxa de criação de empregos } \\
\text { Valor adicionado fiscal do comércio } \\
\text { Massa salarial } \\
\text { Variação da massa salarial em relação ao ano anterior } \\
\text { População } \\
\text { Renda per capita em R\$ correntes }\end{array}$ \\
\hline IDI & $\begin{array}{l}\text { Grau de geração de recursos próprios municipais } \\
\text { Pessoal ocupado em C\&T } \\
\text { IDEB } \\
\text { Agências de Correios } \\
\text { Agências bancárias } \\
\text { Associativismo } \\
\text { Mecanismo de apoio à MPE }\end{array}$ \\
\hline
\end{tabular}

Fonte: SEBRAE, 2011. 
Para verificar as condições sociais e econômicas de cada localidade, foi adotado o IFDM (FIRJAN, 2012), que acompanha três áreas de desenvolvimento: emprego e renda, educação e saúde. Cada um desses componentes é medido conforme as variáveis apresentadas na Tabela 3.

Tabela 3 - Variáveis dos componentes do IFDM

\begin{tabular}{|l|l|}
\hline \multirow{2}{*}{ Emprego e renda } & $\begin{array}{l}\text { Geração de emprego formal } \\
\text { Estoque de emprego formal } \\
\text { Salários médios do emprego formal }\end{array}$ \\
\hline Educação & $\begin{array}{l}\text { Taxa de matrícula na educação infantil } \\
\text { Taxa de abandono } \\
\text { Taxa de distorção idade-série } \\
\text { Porcentual de docentes com ensino superior } \\
\text { Média de horas-aula diárias } \\
\text { IDEB }\end{array}$ \\
\hline Saúde & $\begin{array}{l}\text { Número de consultas pré-natal } \\
\text { Óbitos por causas mal definidas } \\
\text { Óbitos infantis por causas evitáveis }\end{array}$ \\
\hline
\end{tabular}

Fonte: FIRJAN (2012).

Em relação ao índice de desenvolvimento escolhido, vale mencionar que o IFDM é um entre aqueles atualmente utilizados no Brasil. A opção por ele se deve a algumas vantagens apresentadas em relação aos demais. O IDH municipal (IDH-M), o mais reconhecido, tem periodicidade reduzida, pois utiliza exclusivamente as informações dos censos populacionais, realizados decenalmente. No fim de abril de 2013, o site do Programa das Nações Unidas para o Desenvolvimento (PNUD) informava que os dados do Censo 2010 ainda estavam sendo trabalhados, e a previsão era de que o IDH-M fosse lançado no primeiro semestre de 2013 (PNUD, 2013).

Outro indicador é o Índice Ipardes de Desenvolvimento Municipal (IPDM), criado pelo Instituto Paranaense de Desenvolvimento Econômico e Social (IPARDES, 2012), bastante semelhante ao IFDM, mas com algumas particularidades que tornariam inviável a comparação com os dados de outros estados. Assim, optou-se pelo IFDM em razão de sua periodicidade anual e do fato de ser calculado igualmente para todos os 5.564 municípios brasileiros.

\subsection{Análise}

Com o uso da técnica AED, observou-se que o gráfico de dispersão com base nos dados apresentou a inexistência de outliers e, por isso, a pesquisa foi feita com base na amostra total $(n=399)$. 
Para se investigar a relação entre os indicadores IDMPE e IFDM, usou-se o coeficiente de correlação de Pearson, a partir do programa SPSS 16.0 para Windows.

Este coeficiente de correlação (r) foi desenvolvido por Karl Pearson e Francis Galton. A correlação "é uma medida de associação linear entre variáveis" (FIGUEIREDO FILHO; SILVA JÚNIOR, 2009, p. 118). O coeficiente pode variar de -1 a 1 (os valores de correlação perfeita) e o valor zero significa que não há relação entre os indicadores. Dessa forma, quanto mais perto dos extremos, mais alta é a correlação entre os indicadores, e isso indica que um variará de acordo com o outro.

Não há um consenso quanto à interpretação da magnitude dos coeficientes. A literatura mostra que há autores que consideram grandes os valores entre 0,50 e 1; para outros, a partir de 0,70, a correlação é considerada forte (FIGUEIREDO FILHO; SILVA JÚNIOR, 2009, p. 119). De qualquer maneira, quanto mais perto de 1 (positivo ou negativo), maior é a dependência estatística entre os indicadores.

\subsection{Resultados e discussão}

A correlação simples entre as duas variáveis indica a existência de uma correlação positiva entre $\mathrm{o}$ ambiente favorável às micros e pequenas empresas (IDMPE) e ao desenvolvimento das cidades (IFDM), como se pode constatar nos resultados apresentados na Tabela 4. Conforme a literatura supracitada, esta correlação pode ser classificada como moderada $(r=0,685)$ ou forte.

Como forma de incrementar a análise, também se correlacionou o IDMPE exclusivamente com o componente emprego e renda do IFDM, com objetivo de verificar se a dependência estatística seria maior ao se retirar os indicadores de educação e saúde, que não dependem diretamente da atuação das empresas, como é o caso da geração de postos de emprego e massa salarial. De fato, a correlação encontrada, para os municípios paranaenses, foi ainda mais maior $(r=0,791)$, como apresentado na Tabela 5 .

Os resultados apresentam similitudes com o estudo conduzido por Canever et al. (2010), no qual analisaram a taxa de empreendedorismo e o nível de desenvolvimento dos municípios do Rio Grande do Sul, com conclusões bastante interessantes e que apontam para a correlação entre esses indicadores. Além de confirmarem que o empreendedorismo gera efeitos diretos na renda per capita e no desenvolvimento humano, os autores concluíram que há ainda outros efeitos indiretos a ser contabilizados.

Como as variáveis utilizadas estão disponíveis somente para o Rio Grande do Sul, a pesquisa não pode ser reproduzida em outros locais. Neste estudo, foram considerados a taxa de criação de novas empresas no período de dois anos (1999 e 2000) em relação à população local, além da renda per capita municipal e um indicador de desenvolvimento (Idese) da Fundação de Economia e Estatística (FEE), instituto gaúcho de pesquisa (CANEVER et al., 2010). 
Tabela 4 - Correlação com o IFDM geral

\begin{tabular}{clcc}
\hline & & IDMPE & IFDM \\
\hline \multirow{2}{*}{ IDMPE } & Pearson Correlation & 1 & $0,685^{* *}$ \\
& Sig. (2-tailed) & & 0,000 \\
& $\mathrm{~N}$ & 399 & 399 \\
\hline \multirow{2}{*}{ IFDM } & Pearson Correlation & $0,685^{* *}$ & 1 \\
& Sig. (2-tailed) & 0,000 & 399
\end{tabular}

Fonte: Elaboração dos autores, com base nos dados do SEBRAE e FIRJAN.

Nota: ** Correlation is significant at the 0.01 level (2-tailed).

Tabela 5 - Correlação com IFDM - Emprego e Renda

\begin{tabular}{cc|c|c}
\hline & & IDMPE & $\begin{array}{c}\text { IFDM - Emprego e } \\
\text { Renda }\end{array}$ \\
\hline IDMPE & Pearson Correlation & 1 &, $791^{* *}$ \\
& Sig. (2-tailed) & &, 000 \\
N & 399 & 399 \\
\hline $\begin{array}{c}\text { IFDM }- \\
\text { Emprego e } \\
\text { Renda }\end{array}$ & Pearson Correlation &, $791^{* *}$ & 1 \\
& Sig. (2-tailed) &, 000 & 399
\end{tabular}

Fonte: Elaboração dos autores, com base nos dados do SEBRAE e FIRJAN.

Nota: ** Correlation is significant at the 0.01 level (2-tailed).

Já outras pesquisas sobre a relação entre empreendedorismo e crescimento econômico mostraram resultados diversos, como as de Barros e Pereira (2008) e Fontenele et al. (2011). Contudo, vale observar que a taxa de empreendedorismo, medido pela proporção de trabalhadores por conta própria na população economicamente ativa, foi relacionada ao nível de desemprego e crescimento do PIB. As conclusões deles apontaram o empreendedorismo como forma de garantir renda em ambiente de desemprego.

A literatura mostra que há ainda muita ambiguidade nos estudos, justamente em razão da ausência de uma padronização de dados e da opção por um indicador ou outro. Na introdução do volume 38 da revista Regional Studies, edição especial dedicada ao estudo do empreendedorismo e do desenvolvimento econômico, Acs e Storey (2004) relatam que quatro artigos daquela edição mostram que existe uma relação entre as áreas onde há um aumento na taxa de formação de novas empresas e as que passaram por um desenvolvimento econômico. 
Uma tabela resume os países analisados (Estados Unidos, Reino Unido, Alemanha e Suécia) e as variáveis consideradas, assim como a sua correlação com o desenvolvimento econômico. Entretanto, há algumas ambiguidades no estudo, porque não foram usadas todas as variáveis possíveis. Além disso, a natureza e a escala da defasagem entre a criação de novas firmas e o desenvolvimento não é abordada em todos os artigos. Apesar disso, os autores pontuam que há evidências da ligação entre empreendedorismo e desenvolvimento econômico e que, por isso, os governantes devem incentivar tais atividades.

\section{Conclusão}

O objetivo deste artigo era analisar as relações entre o empreendedorismo e o desenvolvimento local. Mais especificamente, analisou-se se o ambiente favorável ao negócio do micro e pequeno empresário tem alguma relação com as cidades com maior índice de desenvolvimento.

O levantamento mostra que há uma relação positiva entre as duas situações, indicando que cidades que fomentam o empreendedorismo têm mais chances de se desenvolverem socioeconomicamente, e vice-versa. Ficou comprovado que essa relação é ainda mais forte ao se analisar apenas as variáveis econômicas do desenvolvimento local.

O indicador criado pelo Sebrae é uma ferramenta inovadora, pois tenta mensurar não apenas a atividade econômica ou a intenção do micro e pequeno empreendedor, mas também o papel dos governantes locais e o da sociedade civil nessa ação. Ao medir a aderência dos municípios à Lei Geral da Microempresa e ao Plano Diretor de cada cidade (avaliados dentro da subcategoria mecanismos de apoio às MPEs, dentro do indicador IDI), além dos resultados obtidos pela rede municipal no IDEB, o IDMPE permite visualizar como os prefeitos executam o papel de fomentadores do empreendedorismo. Ademais, leva em conta o perfil de associativismo de cada localidade - outra condição importante para a criação de novos negócios e oportunidades.

Há que se dizer que o modelo proposto neste presente estudo também tem limitações. O IDMPE também não está disponível para todas as unidades da federação. Ele foi desenvolvido pelo Sebrae-Paraná e reproduzido em alguns outros estados, como Santa Catarina, Rio Grande do Sul, Mato Grosso do Sul e Pará (SEBRAE, 2011). Entretanto, espera-se que outros escritórios regionais ou até mesmo o Sebrae nacional, que apoiou a criação do IDMPE, universalize a sua aplicação.

Outra limitação se refere à correlação linear, uma vez que ela não é prova de causa e consequência, apenas mostra a relação entre duas variáveis. Portanto, não fica estabelecido que o incentivo ao empreendedorismo gera necessariamente desenvolvimento. Ou, por outra, a possibilidade de isso ocorrer é a mesma de acontecer o inverso: o desenvolvimento socioeconômico de uma cidade gerar um ambiente desfavorável ao empreendedorismo.

Seja como for, o modelo proposto neste presente estudo se inclui na discussão sobre os impactos positivos do empreendedorismo no desenvolvimento local e está aberto a discussões para seu aprimoramento. Fica a sugestão para pesquisas futuras analisarem se há causa e consequência nessa relação, além da possibilidade de se desenvolverem ferramentas que leve em conta os indicadores mais relevantes de empreendedorismo e suas consequências no desenvolvimento humano e que possam ser aplicadas em todo o País.

O IDMPE reforça as vantagens socioeconômicas decorrentes da adoção do incentivo à micro e pequena empresa na forma de política pública de desenvolvimento local. A evolução histórica do Paraná e do Brasil confirma que a desigualdade regional é um problema profundo 
que necessita ser enfrentado de forma diferente da que ocorreu até agora. Incentivos e planos desenhados no âmbito federal e estadual minimizaram pouco as diferenças regionais. Faz-se necessário uma atuação local, que gere resultados mais efetivos. Há caminhos para se fazer isso, e o empreendedorismo pode ser um deles.

\section{REFERÊNCIAS}

ABRUCIO, F. L.; COUTO, C. G. A redefinição do papel do Estado no âmbito local. São Paulo perspect, v. 10, n. 3, p. 40-47, jul./set. 1996. Disponível em: <http://www.seade.gov.br/produtos/spp/index.php?men=rev\&cod=5035>. Acesso em: 29 abr. 2013.

ACS, Z. J.; STOREY D. J. Introduction: Entrepreneurship and economic development. Regional Studies, v. 38, n. 8, p. 871-877, 2004.

AUDRETSCH, D.; KEILBACH, M. Entrepreneurship Capital and Economic Performance. ZEW Discussion Papers 02-76, ZEW - Zentrum für Europäische Wirtschaftsforschung / Center for European Economic Research, 2002. Disponível em: <ftp://ftp.zew.de/pub/zewdocs/dp/dp0276.pdf>. Acesso em: 10 maio 2013.

BARROS, A. A.; PEREIRA, C. M. M. A. Empreendedorismo e crescimento econômico: uma análise empírica. Rev. adm. contemp., Curitiba, v. 12, n. 4, dez. 2008 . Disponível em: <http://www.scielo.br/pdf/rac/v12n4/05.pdf> Acesso em: 10 maio 2013.

BUARQUE, S. C. Metodologia de planejamento do desenvolvimento local e municipal sustentável. Material para orientação técnica e treinamento de multiplicadores e técnicos em planejamento local e municipal. Brasília, junho de 1999.

CANEVER, M. D. et al. Entrepreneurship in the Rio Grande do Sul, Brazil: the determinants and consequences for the municipal development. Econ. Sociol. Rural, Brasília, v. 48, n. 1, mar. 2010.

Disponível

em: $<$ http://www.scielo.br/scielo.php?script=sci_arttext\&pid=S0103-

20032010000100005\&lng=en\&nrm=iso>. Acesso em: 29 abr. 2013.

CUNHA, U. S.; MACHADO, S. A.; FIGUEIREDO FILHO, A. Uso de análise exploratória de dados e de regressão robusta na avaliação do crescimento de espécies comerciais de terra firme da Amazônia. Revista Árvore, Viçosa-MG, v. 26, n. 4, p. 391-402, 2002. Disponível em: <http://www.redalyc.org/articulo.oa?id=48826401>. Acesso em: 29 abr. 2013.

DROUIN, J. Os Grandes Economistas. São Paulo: M. Fontes, 2008.

FIGUEIREDO FILHO, D. B.; SILVA JÚNIOR, J. A. Desvendando os Mistérios do Coeficiente de Correlação de Pearson (r). Revista Política Hoje, v. 18, n. 1, 2009. Disponível em: <http://www.revista.ufpe.br/politicahoje/index.php/politica/article/viewFile/6/6> Acesso em: 29 abr. 2013.

FIGUEIREDO, M. D.; LEITE, E. F. Cidades Empreendedoras: as novas visões sobre planejamento urbano e desenvolvimento econômico no Brasil. Revista Eletrônica de Administração. ed. 53, v. 12, n. 5 set./out.2006.

FIRJAN. IFDM Edição 2012 - Ano Base 2010. Disponível em: <http://www.firjan.org.br/main.jsp?lumChannelId=4028818B3AD121E0013AD19509E21CB 1> Acesso em: 29 abr. 2013.

RBPD - Revista Brasileira de Planejamento e Desenvolvimento, v. 2, n. 2, p. 104-117, jul./dez. 2013. 
FONTENELE, R E. S.; MOURA, H. J.; LEOCADIO, A. L. Capital humano, empreendedorismo e desenvolvimento: evidências empíricas nos municípios do Ceará. RAM, Rev. Adm. Mackenzie (Online), São Paulo, v. 12, n. 5, out. 2011. Disponível em: <http://www.scielo.br/scielo.php?script=sci_arttext\&pid=S1678-

69712011000500008\&lng=en\&nrm=iso>. Acesso em: 10 maio 2013.

FREY, Klaus. Políticas públicas: um debate conceitual e reflexões referentes à prática da análise de políticas públicas no Brasil. Planejamento e Políticas Públicas, Brasília, n. 21, p. 211-259, jun. 2000.

HEIDEMANN, F.G. Do sonho do progresso às políticas de desenvolvimento. In: HEIDEMANN, F. G.; SALM, J. F. (Org.). Políticas Públicas e Desenvolvimento: bases epistemológicas e modelos de análise. 2. ed. Editora Universidade de Brasília, 2009. cap. 1, p. 23-40.

IPARDES. Índice Ipardes de Desempenho Municipal - Nota Metodológica. Curitiba: Ipardes, 2012. Disponível em: <http://www.ipardes.gov.br/pdf/indices/ipdm/nota_metodologica_IPDM.pdf> Acesso em: 29 abr. 2013.

LIMA, W. G. Política pública: discussão de conceitos. Interface (Porto Nacional), n. 5, out. 2012.

MACEDO, M. M.; VIEIRA, V.F.; MEINERS, W.E.M.A. Fases de Desenvolvimento Regional no Brasil e no Paraná: da emergência de um novo modelo de desenvolvimento na economia paranaense. Revista Paranaense de Desenvolvimento, Curitiba, n. 103, p. 5-22, jul./dez. 2002.

MARTINS, R. D; VAZ, J. C.; CALDAS, E. L. A gestão do desenvolvimento local no Brasil: (des)articulação de atores, instrumentos e território. Adm. Pública, Rio de Janeiro, v. 44, n. 3, jun. 2010. Disponível em: <http://www.scielo.br/pdf/rap/v44n3/02.pdf>. Acesso em: 29 abr. 2013.

MEZA, M. L. F. G. Empreendedorismo público: discutindo seus níveis de análise. SILVA, Christian L. da (Org.) Políticas Públicas e Desenvolvimento Local: instrumentos e proposições de análise para o Brasil. Petrópolis, RJ: Vozes, 2012.

PNUD. Ranking do IDH dos Municípios do Brasil 2013. Disponível em: <http://www.pnud.org.br/atlas/ranking/IDH-Globlal-

2013.aspx?indiceAccordion=1\&li=li_Ranking2013>. Acesso em: 29 abr. 2013.

ROCHA, H. STERNBERG, R. Entrepreneurship and Development: The Role of Clusters. Small Business Economics, v. 23, n. 5, p. 363-400, 2005.

SEBRAE. Índice de desenvolvimento municipal para a micro e pequena empresa: Paraná: 2009/2010. Curitiba: SEBRAE/PR, 2011. 99 p.

SEBRAE. Guia do Prefeito Empreendedor - Gestão Municipal 2013-2016. 10 passos e 100 ações - Agenda de Compromissos com os Pequenos Negócios para a Geração de Emprego e Renda. Brasília: Sebrae, 2013.

SILVA. C. L.; LOPES, C.; MICHON JR. W. Intervenção do Estado e desenvolvimento local: uma análise cross section dos municípios paranaenses. Interações, Campo Grande, v. 10, n. 1, p. 41-53, jan./jun. 2009. Disponível em: 〈http://www.scielo.br/pdf/inter/v10n1/05.pdf〉. Acesso em: 29 abr. 2013. 
SILVA. C. L.; MICHON JR. W. Desenvolvimento socioeconômico local e reestruturação produtiva paranaense na década de 1990. Interações, Campo Grande, v. 9, n. 1, p. 29-43, jan./jun. 2008.

Disponível em: <http://www.scielo.br/scielo.php?script=sci_arttext\&pid=S1518-

70122008000100004\&lng=en\&nrm=iso> Acesso em: 29 abr. 2013.

SOUZA, C. Políticas públicas: uma revisão da literatura. Sociologias, Porto Alegre, n. 16 , dez. 2006.

Disponível

em:

<http://www.scielo.br/scielo.php?script=sci_arttext\&pid=S1517-

$45222006000200003 \& \operatorname{lng}=$ pt\&nrm=iso>. Acesso em: 29 abr. 2013.

TOMASETTO, M. Z. C.; LIMA, J. F.; SHIKIDA, P. F. A. Desenvolvimento local e agricultura familiar: o caso da produção de açúcar mascavo em Capanema - Paraná. Interações. Campo Grande, v. 10, n. 1, jun. 2009. Disponível em: $<$ http://www.scielo.br/scielo.php?script=sci_arttext\&pid=S1518$70122009000100003 \& \operatorname{lng}=e n \& n r m=i s o>$ Acesso em: 29 abr. 2013. 